\title{
Tendências da fecundidade dos povos indígenas nos Censos Demográficos brasileiros de 1991 a 2010*
}

\author{
Laura L. Rodríguez Wong ${ }^{\star \star}$
}

0 artigo aborda a fecundidade das mulheres autodeclaradas indígenas com base nos censos brasileiros de 1991 a 2010. Inicialmente - como uma aproximação das limitações que a qualidade do dado pode impor às análises - observa-se um viés de autodeclaração para 2000 mais acentuado na população urbana, o que compromete as comparações com 2010, mas não invalida o prosseguimento das análises sobre fecundidade. Constata-se que, efetivamente, a fecundidade dos povos indígenas está diminuindo inclusive entre a população rural, isto é, aquela que reside em Terras Indígenas. A fecundidade indígena urbana é altamente diferenciada da rural e as suspeitas de o viés estar contaminando as medidas produzidas evidenciam a necessidade de um investimento maior no estudo desta população: quem são os indígenas urbanos? Estimativas por ordem de parturição e filhos tidos sinalizam acentuadas quedas de fecundidade para o futuro próximo. A fecundidade das mulheres indígenas jovens - sem muitas diferenciações segundo residência urbana ou rural - continua em níveis muito altos se comparados com os de populações contemporâneas. Esta análise clama por estudos multidisciplinares para o melhor entendimento do processo reprodutivo dos povos indígenas brasileiros.

Palavras-chave: Demografia indígena. Fecundidade. Ordem de nascimento.

\footnotetext{
* A autora agradece a cuidadosa revisão dos pareceristas e dos editores da Rebep e reconhece como exclusivamente suas as limitações do presente artigo. A autora agradece ainda o auxílio de Gabriela de Oliveira Bonifácio e Juliana Vasconcelos, assistentes de pesquisa do Cedeplar, pela colaboração com a produção dos indicadores, bem como o suporte recebido do CNPq no programa apoio ao pesquisador individual.

${ }^{\star *}$ Centro de Desenvolvimento e Planejamento Regional (Cedeplar), Departamento de Demografia da Faculdade de Ciências Econômicas (Face), Universidade Federal de Minas Gerais (UFMG), Belo Horizonte-MG, Brasil (lwong@cedeplar.ufmg.br).
} 


\section{Introdução}

Durante a primeira metade do século XX, o crescimento da população brasileira manteve-se alto e constante, com taxas médias anuais em torno de $3 \%$, consequência da queda da mortalidade e da constância dos elevados níveis de fecundidade. É bastante conhecida a rápida transição da fecundidade que, a seguir, tomaria conta do país, assim como de grande parte do continente latino-americano, de forma tal que, ao se inaugurar o segundo quinquênio dos anos 2010, pouco se duvida desse franco e generalizado declínio. No caso do Brasil, em alguns estados, uma fecundidade em torno de 1,5 filho por mulher é praticamente a norma. Em São Paulo, por exemplo, a Fundação Seade mostra, com seus dados até 2015, que haveria apenas duas regiões administrativas (Santos e Registro) com níveis pouco acima desse valor. ${ }^{1}$ Semelhante afirmativa é válida para Rio Grande do Sul (TONON, 2015). Em algumas regiões e grupos socioeconômicos, a fecundidade já teria se consolidado em níveis bastante baixos, com poucos sinais de alguma recuperação no curto prazo.

Com relação aos povos indígenas, existem evidências de um processo de recuperação populacional na década passada (PAGLIARO, 2002; SOUZA; SANTOS, 2001), posteriormente acompanhado por um arrefecimento causado pela redução da fecundidade. Pagliaro et al. (2004) encontraram evidências esparsas de que, em alguns povos indígenas, a fecundidade estaria diminuindo. As estimativas de fecundidade a partir dos dados do Censo de 2000 confirmaram que este segmento da população não fugiu da tendência generalizada de queda, embora com indicativos de ter sido principalmente entre aqueles residentes fora de Terras Indígenas, ou seja, em áreas urbanas e rurais não indígenas (WONG; MORELL; CARVALHO, 2009). No entanto, Vitti e Junqueira (2015) apresentam dados longitudinais de mulheres kamaiurá, observadas em 2009, em que - de forma perturbadora, talvez, para alguns pesquisadores - se verifica uma diminuição da fecundidade da ordem de $50 \%$ para coortes de mulheres relativamente mais jovens em comparação às coortes apenas cinco anos mais velhas.

Em estudo anterior, Wong, Morell e Carvalho (2009) realizaram uma análise sobre a fecundidade urbana e rural da população indígena, utilizando os dados dos Censos Demográficos de 1991 e 2000. Segundo as autoras, a fecundidade nas áreas urbanas era muito menor do que na rural, além de a tendência futura indicar uma redução ainda maior, principalmente se a população indígena urbana continuar aumentando devido à migração rural-urbana.

No Censo Demográfico de 2010 se supõe que o levantamento da população indígena tenha melhorado, visto que a pergunta sobre raça/cor passou a fazer parte do questionário do universo do censo, evitando, pelo menos, que erros amostrais em uma população pequena afetem os resultados (IBGE, 2013). Nesse sentido, o objetivo do presente trabalho é analisar o nível e padrão da fecundidade das mulheres autodeclaradas indígenas em 2010,

\footnotetext{
${ }^{1}$ Disponível em: 〈http://produtos.seade.gov.br/produtos/mrc/〉. Acesso em: 12 out. 2016.
} 
comparando, na medida do possível, com as estimativas de 1991 e 2000, para inferir sobre as tendências observadas para a reprodução da população indígena.

Deve-se ressaltar que as informações mais adequadas para calcular indicadores de fecundidade no Censo Demográfico estão na base de microdados de uso público da amostra, para a qual não foram divulgadas as informações sobre etnia, língua falada e Terras Indígenas, que estão disponíveis somente nos dados do universo (IBGE, 2012). Assim, este artigo utiliza o recorte populacional da população feminina autodeclarada indígena, que, se reconhece, é um segmento populacional muito heterogêneo. No entanto, o artigo certamente contribuirá para um melhor entendimento do comportamento reprodutivo desta população, principalmente comparando-se com dados observados nas duas décadas passadas.

A primeira parte do artigo considera algumas generalidades, como as definições censitárias sobre etnia e a coerência da informação coletada nos três pontos no tempo. A seguir apresentam-se medidas do nível e padrão da fecundidade, com o objetivo de definir as tendências do período 1991-2010. Para buscar respostas sobre possíveis mudanças no calendário da fecundidade, incluem-se também estimativas da taxa específica de fecundidade por idade e ordem de nascimento para nascimentos ocorridos no ano anterior ao censo. Finalmente, dados de parturição e total de filhos tidos são analisados mediante a técnica proposta por Brass (1985), a fim de estimar tendências da fecundidade no curto prazo. 0 nível de desagregação limita-se à condição de residência urbana ou rural, sem discriminar, neste caso, a população indígena residente em Terras Indígenas, uma vez que a maioria da população indígena rural (86\%) reside nessas áreas (IBGE, 2010).

\section{Os dados sobre população in dígena nos Censos Demográficos de 1991, 2000 e 2010}

Em função das conhecidas dificuldades de comparação entre os censos recentes sobre povos indígenas, este item apresenta, após uma referência à classificação raça/cor nos censos brasileiros, a evolução da população dos povos indígenas, seja para o total, seja para os segmentos objetos de análise deste trabalho - as mulheres em idade fértil e as crianças menores de cinco anos -, no sentido de ilustrar algumas das restrições que a qualidade da informação impõe às análises.

A investigação sobre cor/raça nos censos brasileiros, como se sabe, data do primeiro levantamento realizado no país, em 1872. São vários os estudos, como os de Oliveira (1997), Piza e Rosemberg (1999) e IBGE (2005), que, com um olhar crítico, fazem um inventário de como a etnia tem sido coletada ao longo da história censitária do país e cujo detalhamento foge ao escopo deste artigo. Basta mencionar que o critério predominante, com algumas variações, tem sido o da "autodeclaração" e, desde 1991, incorpora a categoria "indígena" - que nos censos anteriores era classificada provavelmente na categoria "parda". 0 critério de autodeclaração na definição de raça ou etnia obedece à necessidade de se ter uma definição operativa do que é o povo indígena e, acima de tudo, de preservar 
o direito individual de identificação e reconhecimento na sociedade como pertencente ao povo nativo do país. ${ }^{2}$

Deve-se salientar também que, no caso das etnias afrodescendente e indígenas brasileiras, vivencia-se um contexto difuso de segregação não explícita, em que simultaneamente há intervenções e políticas expressas que, com maior ou menor sucesso, despertam a consciência sobre pertencimento a estas etnias. Tal circunstância, juntamente com a subjetividade que a resposta carrega, torna complexa a comparação intercensitária das mesmas, uma vez que a autoidentificação flutuaria de acordo com a autoafirmação, grau de informação, educação e pressões sociais de diversas índoles. ${ }^{3} \mathrm{~A}$ permanência da informação sobre cor/raça ao longo dos três últimos censos, contudo, incrementa exponencialmente as possibilidades de análise, permitindo acompanhar a evolução histórica das etnias segundo quaisquer das características coletadas nestes três censos e, particularmente, o perfil reprodutivo das mulheres indígenas.

A Tabela 1 apresenta as taxas de crescimento para a população total, o grupo de mulheres em idade fértil, que é o foco do presente artigo, e as crianças menores de cinco anos, para a população indígena e não indígena no período analisado. Os dados mostram, ao mesmo tempo, as possibilidades e as dificuldades de fazer uma reconstrução histórica recente deste segmento populacional. Para a população brasileira não indígena - que representa mais de $99 \%$ do total do país -, o crescimento registrado pelos censos situou-se nos intervalos esperados para uma população que já vinha mostrando tendência de diminuição, em função, no caso urbano, do comportamento vegetativo com baixa natalidade e, no rural, da redução do próprio volume - além do baixo crescimento vegetativo - relacionada à atração exercida pelas cidades com altos fluxos migratórios.

Note-se que, ao longo de um período de quase 20 anos, a população rural não indígena apresentou taxas de crescimento médio anual negativas. Tendência similar se observa entre a população feminina não indígena em idade fértil. No caso das crianças com menos de cinco anos de idade, segmento utilizado aqui como primeira aproximação do fenômeno reprodutivo, em que pesem as dificuldades de captação, confirma-se também o que se conhece sobre a fecundidade brasileira: uma diminuição tão acentuada que se reflete - inclusive em termos absolutos - na redução dos nascimentos. Todavia, a taxa capta o fenômeno já presente em períodos anteriores aos aqui considerados para a área urbana e sua presença mais recente na área rural.

No caso dos povos indígenas, os dados da Tabela 1 mostram, como amplamente analisado, taxas médias de crescimento incomuns para períodos intercensitários. A situação mais inusitada foi registrada entre 1991 e 2000 para as áreas urbanas, com taxas médias acima de $10 \%$ ao ano. Embora seja factível de justificação esperar taxas destas magnitudes em populações pequenas expostas a fortes deslocamentos, não parece ser

\footnotetext{
${ }^{2}$ Trata-se de um dos direitos humanos, pactuado na International Covenant on Economic, Social and Cultural Rights (1966), adotado e ratificado pela Assembleia Geral de 1966 das Nações Unidas.

${ }^{3}$ Ver, sobre isso, as reflexões de Silva (1999), Gonçalves e Gonçalves e Silva (2000), entre outros.
} 
esta a explicação aceita por estudiosos dos povos indígenas. Para Oliveira et al. (2005), que endossam a posição de Azevedo e Ricardo (2002), é pacífico assumir que isso se deve, em grande parte, ao

[...] aumento da proporção de índios urbanizados que optaram pela identificação 'indígena' e que se classificaram como 'pardos' em censos anteriores e ampliação do contingente de pessoas que se classificaram genericamente como 'indígenas', ainda que não se identificando com etnias específicas. (AZEVEDO; RICARDO, 2002 apud OLIVEIRA et al., p. 164).

As hipóteses associadas ao pressuposto de melhor cobertura censitária em territórios indígenas, o processo de conscientização e valorização da cultura dos povos indígenas que teria encorajado os indivíduos a se declararem indígenas, as políticas de cotas de inclusão social e os benefícios sociais de transferência de renda são, também, endossadas por Brasil e Teixeira (2006) e Wong, Morell e Carvalho (2009).

TABELA 1

Taxas de crescimento médio anual da população indígena e não indígena, segundo segmentos populacionais e situação de domicílio

Brasil - 1991-2010

Em porcentagem

\begin{tabular}{|c|c|c|c|c|c|c|}
\hline \multirow{2}{*}{ Situação de domicílio } & \multicolumn{3}{|c|}{ Não indígena } & \multicolumn{3}{|c|}{ Indígena } \\
\hline & $1991-2000$ & $2000-2010$ & $1991-2010$ & $1991-2000$ & $2000-2010$ & $1991-2010$ \\
\hline \multicolumn{7}{|l|}{ População total } \\
\hline Total & 1,6 & 1,2 & 1,4 & 10,2 & 1,1 & 5,4 \\
\hline Urbana & 2,4 & 1,6 & 2,0 & 18,7 & $-2,0$ & 7,8 \\
\hline Rural & $-1,4$ & $-0,7$ & $-1,0$ & 5,0 & 3,6 & 4,3 \\
\hline Proporção da população rural (\%) & 24,3 & 18,6 & 15,4 & 75,9 & 47,8 & 61,5 \\
\hline \multicolumn{7}{|l|}{ Mulheres de 15 a 49 anos } \\
\hline Total & 2,2 & 1,3 & 1,7 & 11,7 & 1,3 & 6,2 \\
\hline Urbana & 2,9 & 1,6 & 2,2 & 19,4 & $-2,4$ & 7,9 \\
\hline Rural & $-0,8$ & $-0,3$ & $-0,5$ & 5,1 & 5,3 & 5,2 \\
\hline Proporção da população rural (\%) & 20,6 & 15,7 & 13,4 & 68,9 & 38,0 & 57,0 \\
\hline \multicolumn{7}{|l|}{ Crianças de 0 a 4 anos } \\
\hline Total & $-0,1$ & $-1,8$ & $-1,0$ & 6,4 & 3,1 & 4,6 \\
\hline Urbana & 0,9 & $-1,2$ & $-0,2$ & 15,2 & $-0,7$ & 6,9 \\
\hline Rural & $-3,2$ & $-4,0$ & $-3,6$ & 4,3 & 4,1 & 4,2 \\
\hline Proporção da população rural (\%) & 29,0 & 21,9 & 17,6 & 87,8 & 72,9 & 81,4 \\
\hline
\end{tabular}

Fonte: IBGE. Censos Demográficos de 1991, 2000 e 2010.

O comportamento incomum entre 1991 e 2000 é similar para mulheres em idade fértil dos povos indígenas. Já no que se refere ao surgimento das novas gerações ou coortes (representadas aqui pela população de 0 a 4 anos), observa-se um aumento médio anual constante de pouco mais de $4 \%$ ao longo das duas décadas para a população indígena. 
Mesmo que a onda eufórica de 2000 de autodeclaração como membro de um povo indígena tenha arrefecido em 2010, certamente a aferição de qualquer tendência, principalmente entre 1991 e os demais anos, estará contaminada e deve ser analisada com cuidado. 0 crescimento registrado para o período intercensitário seguinte (2000-2010) dos povos indígenas, seja para o total dessa população, seja para as mulheres em idades reprodutivas, padeceria menos dessa contaminação.

Dessa forma, não sem temor do efeito de contaminação e da presença do despertar para o sentimento de pertencimento a uma etnia indígena, pode-se afirmar que os povos indígenas estão ainda em fase de importante crescimento populacional. 0 mesmo aplica-se à população em idade fértil, o que, em certa medida - guardadas as considerações sobre a qualidade da informação neste grupo etário - é confirmado pelas taxas registradas para as crianças de 0 a 4 anos.

A representatividade da população rural nos correspondentes grupos considerados reforça o que foi mencionado. Na população não indígena, sabe-se, a participação da população rural vem diminuindo constantemente e esta tendência está menos clara nos povos indígenas, segundo os resultados censitários. Observa-se, na Tabela 1, que a proporção de população indígena nas áreas rurais reduziu-se acentuadamente entre 1991 e 2000, com maior ênfase entre as mulheres em idade fértil. Já para 2010, a proporção aumentou sem, no entanto, superar aquela registrada em 1991. Se o Censo de 2010 possui maior grau de confiabilidade, mostrando que o crescimento vegetativo da população indígena é acentuadamente maior na população rural haja vista a proporção mais elevada dos menores de cinco anos, independentemente dos deslocamentos entre áreas urbana e rural, taxas médias anuais acima de $4 \%$ ao longo de quase 20 anos neste grupo etário é forte indicativo do ainda alto crescimento do povo indígena. Estes dados sugerem, por último, que a população indígena continua sendo principalmente rural e, assim, se houve vieses de autodeclaração e se estes foram mais acentuados na população urbana, a análise para o total da população e principalmente para os indígenas residentes em áreas rurais não estaria significativamente comprometida. Entretanto, devido a estes problemas na contagem geral da população entre os censos, os indicadores de fecundidade precisam de métodos que utilizam dados de cada ano para as estimativas e, obviamente, não de métodos que usam mais de um censo para as estimativas pontuais.

\section{A fecundidade dos povos indígenas}

Nesta seção apresentam-se alguns indicadores do perfil reprodutivo das mulheres indígenas. Inicialmente, o comportamento geracional constitui uma tentativa de estimar a evolução da parturição (ou número médio de filhos) por idade das mulheres nos três censos. As estimativas clássicas de fecundidade (taxa de fecundidade total e taxas específicas) são incluídas com o intuito de estabelecer a tendência da fecundidade dos povos indígenas. Em função das restrições anteriormente mencionadas, é dada maior atenção às 
medidas para a população rural, mostrando o perfil da fecundidade por idade e, também, por ordem de parturição.

\section{A parturição das coortes ou gerações captadas nos três censos}

O número médio de filhos nascidos vivos - ou parturição -, por ser uma medida de estoque e que, consequentemente, aumenta com a idade da mulher, é um indicativo da experiência acumulada da fecundidade. Ao mesmo tempo, com estatísticas que abrangem o universo, como é o caso do censo, é possível, mediante um enfoque longitudinal, uma aproximação do comportamento das coortes ou gerações presentes nos registros censitários.

No presente caso tem-se a parturição das mulheres com determinada idade no primeiro censo e nos censos seguintes. Assim, por exemplo, sabe-se qual é a parturição da mulher que estava no grupo etário 35-39 anos, no censo de 2000, e quando ela estava no grupo etário 45-49 anos, no censo 2010. Assumindo que os dados de 1991 são representativos das mulheres um ano mais jovens (isto é, em 1990), é possível definir a parturição das mulheres recenseadas no primeiro momento e ao longo de um período de 20 anos. ${ }^{4}$ No Gráfico 1 , que mostra tal reconstrução, observam-se, por exemplo, a parturição média das jovens com idades de 15 a 19 anos, em 1991, e o valor correspondente quando elas eram, aproximadamente, dez e 20 anos mais velhas (nos grupos etários 25-29 e 35-39 anos, respectivamente). 0 mesmo se verifica para as coortes com de 20-24 e 25-29 anos, respectivamente.

\section{GRÁFICO 1}

Número médio de filhos nascidos vivos para três coortes de mulheres indígenas de 15-19, 20-24 e 25-29 anos (1) em 1991 e captado em 1991, 2000 e 2010 (2), segundo situação de domicílio

Total

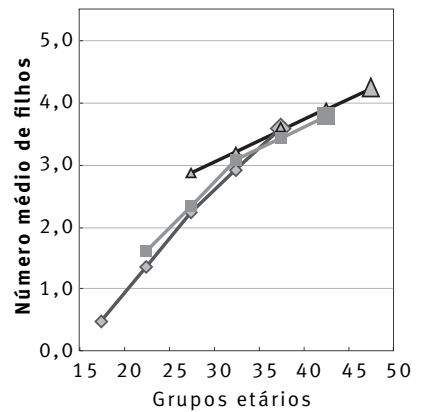

$\multimap 15$ a $19(1991)$

\section{Brasil - 1991-2010}

Urbana

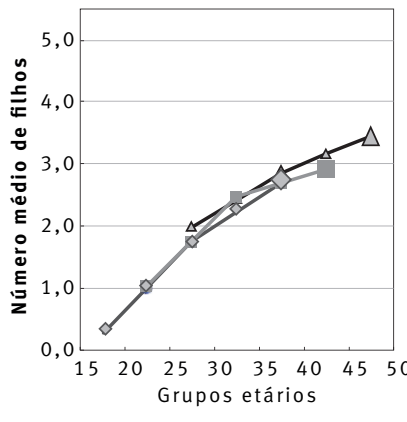

-20 a $24(1991)$
Rural

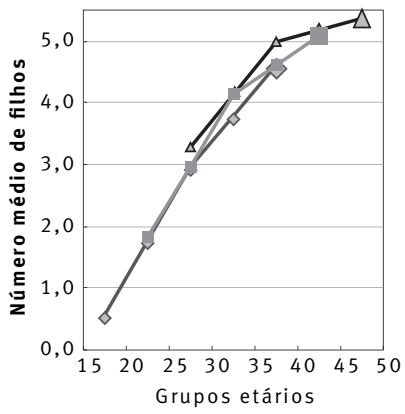

-25 a $29(1991)$

Fonte: IBGE, microdados dos Censos Demográficos de 1991, 2000 e 2010, conforme mostrados na Tabela 1 do Apêndice. (1) Refere-se ao seguimento da coorte de idade especificada em 1991. Isto é, a coorte que em 1991 tinha de 15 a 19 anos pode ser identificada no Censo de 2000, quando as mulheres desta coorte estariam nove anos mais velhas (grupo etário 24-28) e, em 2010, quando estariam 19 anos mais velhas (grupo etário 34-38). Para efeito de simplificação, assume-se que esses grupos etários têm experiência reprodutiva similar aos grupos etários tradicionais (25-29 e 25-39 anos).

(2) 0 marcador de maior tamanho em cada curva que representa as coortes corresponde ao número médio de filhos captado em 2010.

\footnotetext{
${ }^{4}$ Assumindo: que se trata-se de uma população fechada, o que não é o caso da população urbana, mesmo que seu volume seja pequeno; que não há mortalidade diferencial segundo parturição, caso contrário, se mulheres de alta parturição têm maior risco de morrer, as estimativas para as mulheres mais velhas estariam subestimadas.
} 
O aumento da parturição por idade está consistentemente presente nas três situações (total, urbana e rural). Para a geração mais velha - aquela com 25 a 29 anos em 1991 -, o número médio de filhos por mulher ao final do período reprodutivo, captado em 2010 - quando elas estavam no grupo etário 45-49 anos - foi de pouco mais de quatro filhos para o total da população indígena. Os dados desagregados por condição de residência urbana ou rural mostram o diferencial esperado: a parturição final para as mulheres da área urbana correspondeu a 3,5 filhos, enquanto a daquelas da área rural foi superior a 5,0 filhos. Com relação à tendência no tempo, os dados sugerem pouca mudança no número médio de filhos que as mulheres têm. Nos grupos etários em que a comparação por coorte é possível (idades 30-34 e 35-39 anos), há, no geral, coincidência no número de filhos que as mulheres de diferentes gerações apresentam na mesma idade. Comportamento igual é verificado na desagregação por áreas urbana e rural.

Em síntese, a parturição das coortes, captada nos três censos, apresenta-se bastante coerente. À parte o esperado aumento por idade, o diferencial segundo áreas de residência registra níveis significativamente baixos para o segmento urbano. A parturição, que como dito é um indicador do estoque da fecundidade, não mostra evidências de queda da fecundidade entre as coortes, com o que a diminuição da fecundidade seria um fenômeno muito próximo a 2010, não captada ainda na parturição das mulheres mais velhas.

\section{O nível e o padrão por idade da fecundidade dos povos indígenas}

Esta seção apresenta os níveis da fecundidade da população autodeclarada indígena, assim como o seu comportamento por idade. As estimativas anteriores a 2010 foram replicadas de Wong, Morell e Carvalho (2009) e seguem a mesma metodologia. ${ }^{5} 0$ Gráfico 2 e a Tabela 2 sintetizam o conjunto de indicadores do perfil reprodutivos das mulheres indígenas brasileiras.

Lembrando os possíveis vieses sobre a identificação dos povos indígenas nos censos, a visão de conjunto no Gráfico 2 mostra vários aspectos do perfil da fecundidade:

- para a população indígena total, a fecundidade por idade é relativamente maior em 1991 e teria diminuído no censo seguinte, permanecendo constante entre 2000 e 2010. Como mostrado na Tabela 2, as taxas de fecundidade total (TFT), nesses anos, corresponderam a 5,4, 3,9 e 3,8 filhos, respectivamente;

- a mencionada tendência é definida pelo comportamento da população indígena rural, que a replica dada sua representação majoritária;

\footnotetext{
${ }_{5}^{5}$ Foi aplicado o método de Brass (1973) que utiliza informação retrospectiva sobre o número total de filhos tidos nascidos vivos, ou seja, a longo da vida reprodutiva da mulher (como uma medida de estoque, ou fecundidade acumulada) e filhos nascidos vivos nos 12 meses anteriores à data do censo (como uma medida da fecundidade corrente, ou atual). A comparação de ambos indicadores permite eventualmente ajustar os dados para obter medidas de fecundidade.
} 
- a população rural mostra altos níveis de fecundidade para as décadas anteriores, beirando em alguns casos os limites biológicos: as taxas para o grupo de etário 20 a 24 anos, por exemplo, indicavam perto de 300 nascidos vivos por mil mulheres dessas idades. Este valor é encontrado apenas em nações de extrema vulnerabilidade, como, por exemplo, alguns países do grupo categorizado como least developed countries para as décadas passadas (UNITED NATIONS, 2015);

- não se observam mudanças significativas para mulheres indígenas urbanas, devendo-se salientar que os menores valores foram registrados no Censo de 2000;

- o diferencial da fecundidade segundo áreas de residência mostra níveis acentuadamente menores para a população urbana nos três momentos censitários. Particularmente em 2000, a diferença em alguns grupos etários superava 100\% (Tabela 2, do Apêndice). Para 2010, o acentuado diferencial permanece, embora devido essencialmente aos menores valores registrados para indígenas das áreas rurais;

- chama a atenção, também, o comportamento das taxas para o grupo mais jovem (15-19 anos). Atendendo ao nível definido para 2010 na área rural (173,1 nascidos vivos para cada mil jovens), vale salientar que valores similares dificilmente são encontrados na atualidade; os poucos casos correspondem novamente a países de alta vulnerabilidade socioeconômica, e nem países com alta representatividade de população indígena - inclusive nos arquipélagos asiáticos - apresentam valores tão altos (UNITED NATIONS, 2015). Mesmo para as áreas urbanas, taxas acima de 100 nascidos vivos por mil mulheres muito jovens são um alerta do potencial de vulnerabilidade a que esta população se expõe.

GRÁFICO 2

Taxas específicas de fecundidade (TEF) das mulheres indígenas, por grupos de idade, segundo situação de domicílio

Brasil - 1991-2010
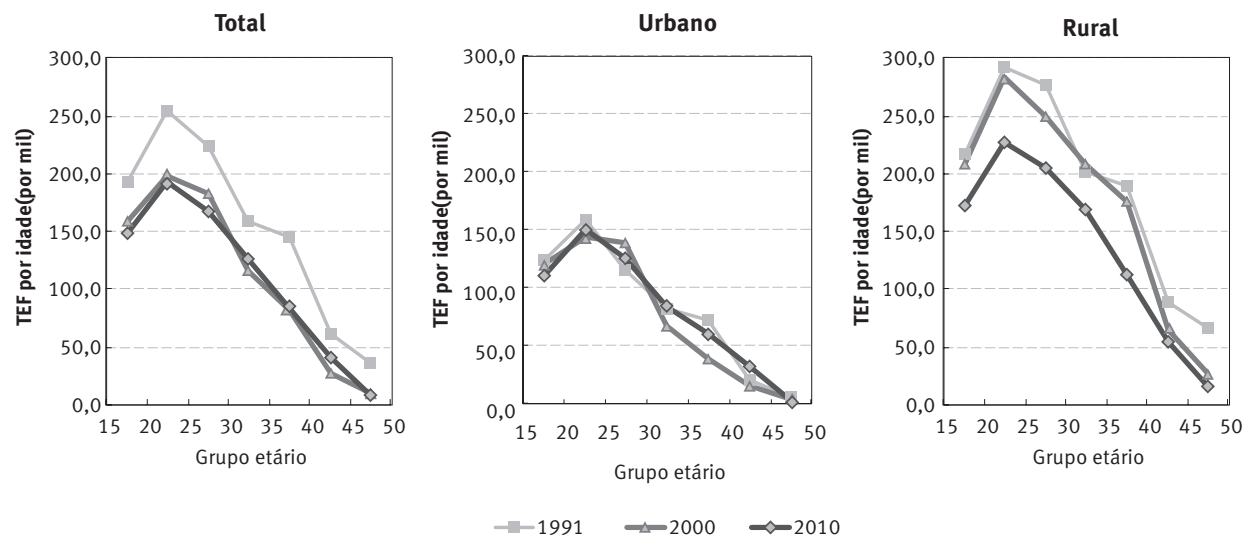

Fonte: Wong, Morell e Carvalho (2009) para dados de 1991 e 2000; IBGE. Microdados do Censo Demográfico 2010. 
Os indicadores da Tabela 2 contribuem para um melhor entendimento desse perfil descrito. Com relação ao nível da fecundidade - sintetizado pela TFT -, há pouca dúvida a respeito de sua diminuição, devido, essencialmente, à retração registrada na população rural, fenômeno que, provavelmente, manifestou-se na última década. A população indígena urbana com ou sem viés de autodeclaração apresenta níveis relativamente muito baixos (2,8 filhos por mulher). Wong, Morell e Carvalho (2009), ao analisarem as diversas regiões do Brasil, aceitam estes níveis sem discutir a confiabilidade da autodeclaração; em 2010, a TFT de mulheres indígenas urbanas parece ter se mantido nos mesmos baixos patamares, embora com ligeiro aumento. As indígenas rurais apresentam TFT elevada, próxima de 5 filhos por mulher.

A idade média da distribuição da fecundidade mostra uma ligeira tendência à diminuição se considerados o primeiro e o último censos. Trata-se de uma característica própria de um processo de transição da fecundidade, em que as mulheres mais velhas num primeiro momento são as que proporcionalmente diminuem mais seus riscos de fecundidade fenômeno típico de América Latina. ${ }^{6} 0$ desdobramento deste indicador segundo lugar de residência mostra coerência com as considerações até aqui apresentadas: na área urbana, as mudanças, apesar de erráticas, registram, para 1991 e 2010, valores similares (em torno de 27 anos). Se as taxas não apresentaram mudanças, independentemente de quem se autodeclara indígena na área rural, não deveriam ser esperadas alterações, o que efetivamente teria acontecido. Já no caso da população rural, a mudança para uma distribuição mais jovem é clara e deve-se, essencialmente, à mais acentuada diminuição verificada, entre 1991 e 2010, para as mulheres mais velhas. Com efeito, entre as mulheres com idades inferiores a 30 anos, a taxa de fecundidade diminuiu um quinto aproximadamente; já entre aquelas de 35 anos e mais, as taxas de 2010 foram, em média, 50\% inferiores (Tabela 2 do Apêndice). 0 padrão etário da fecundidade das mulheres indígenas é descrito, também, mediante o papel que elas têm, segundo a idade. Ainda na Tabela 2, observa-se, por exemplo, a alta contribuição para a fecundidade das jovens menores de 20 anos. No geral, elas são responsáveis por, aproximadamente, $20 \%$ de toda a fecundidade; todavia, o padrão jovem sumarizado pela idade média mostra a participação das mulheres com menos de 30 anos: no geral, dois terços do total da fecundidade devem-se a estas mulheres. Finalmente, aquelas com 40 anos ou mais contribuem escassamente para o total da fecundidade, com uma tendência a contribuir cada vez menos, excetuando a população indígena urbana. Para efeitos comparativos, lembre-se que, entre a população não indígena, a fecundidade das mulheres nestas idades foi inferior a 1\% em 2010. Estas constatações são de essencial importância para efeitos de planejamento da saúde reprodutiva, em particular, e da saúde integral, no geral.

\footnotetext{
${ }^{6}$ Ver, por exemplo, as tendências apresentadas para os países latino-americanos nas estimativas de fecundidade por idade da United Nations (2015).
} 
Wong, L.L.R. Tendências da fecundidade dos povos indígenas nos Censos Demográficos brasileiros de 1991 a 2010

TABELA 2

Taxas de fecundidade total das mulheres indígenas, idade média da fecundidade e contribuição para o total da fecundidade nas idades indicadas, segundo situação de domicílio Brasil - 1991-2010

\begin{tabular}{llccc}
\hline \multicolumn{1}{c}{ Indicadores de fecundidade } & $\begin{array}{c}\text { Situação de } \\
\text { domicílio }\end{array}$ & $\mathbf{1 9 9 1}$ & $\mathbf{2 0 0 0}$ & $\mathbf{2 0 1 0}$ \\
\hline \multirow{2}{*}{ Taxa de fecundidade total (1) } & Total & 5,4 & 3,9 & 3,8 \\
& Urbano & 2,9 & 2,6 & 2,8 \\
& Rural & 6,7 & 6,1 & $\mathbf{4}, 8$ \\
\hline \multirow{2}{*}{ Idade média da fecundidade (em anos) } & Total & 28,2 & 26,7 & 27,0 \\
& Urbano & 26,7 & 25,8 & 27,8 \\
\hline Contribuição para o total da fecundidade & Rural & 29,0 & 28,2 & 19,4 \\
& & & & 19,6 \\
nas idades indicadas (\%) & Total & 18,0 & 20,6 & 18,1 \\
\hline \multirow{2}{*}{ Menos de 20 anos } & Urbano & 21,5 & 22,8 & 66,4 \\
& Rural & 16,2 & 17,2 & 68,2 \\
Menos de 30 anos & Total & 62,5 & 69,7 & 63,2 \\
\hline
\end{tabular}

Fonte: IBGE. Censo Demográfico 2010; Wong, Morell e Carvalho (2009).

(1) Todas as taxas de 2010 foram corrigidas em 1,9\%, fator obtido da aplicação do método de Brass. Para 1991 e 2000, segundo Wong et al. (2009), os fatores foram 1,14\% e 1,16\%, respectivamente. Em todos os casos foi considerado um fator único para a população total, urbana e rural, obtido a partir das idades 20 a 29 anos.

\section{A fecundidade dos povos indígenas das áreas rurais - 2000 e 2010}

As evidências anteriores indicam que as estimativas mais confiáveis parecem ser aquelas correspondentes a 2010, além de apontarem que a fecundidade dos povos indígenas das áreas rurais provavelmente iniciou a transição a níveis menores na década passada, embora indígenas residentes nas áreas urbanas mostrem níveis bastante mais baixos desde pelo menos 1991. Com tais considerações, nesta seção detalha-se, em primeiro lugar, o perfil da fecundidade destes povos levando em conta a ordem de parturição das mulheres, isto é, como opera a fecundidade segundo o número de filhos já tidos pelas mulheres. Finalmente, num intento de vislumbrar o comportamento futuro, são realizadas algumas prospecções.

A fecundidade dos povos indígenas por idade e ordem de nascimento

A chance de ter um nascido vivo pode ser medida, também, pelo número de filhos que a mulher já tem, obtendo-se, assim, taxas específicas de fecundidade por idade segundo ordem de nascimento. Estas taxas foram calculadas a partir da informação sobre fecundidade atual, isto é, com base nas respostas sobre nascimentos ocorridos 
durante os 12 meses prévios ao censo, devidamente ajustados pelos fatores de correção obtidos para os totais. ${ }^{7}$

O Gráfico 3 mostra o padrão da fecundidade por idade nos diversos grupos etários, segundo ordem de nascimento para 2000 e 2010. Na parte superior do Gráfico 3 apresentam-se taxas de fecundidade para nascimentos até ordem 4 e, para melhor visualização, as ordens seguintes na parte inferior. Se considerados os nascimentos de ordem 1 , as maiores taxas concentram-se, como seria de se esperar, na população mais jovem. Particularmente, as mulheres no grupo de 15 a 19 anos são responsáveis por $50 \%$ do total destas taxas sem mudança desta proporção nos dois períodos. Adicionalmente, o valor da taxa para este grupo é, também, semelhante, ficando próxima de 90 nascimentos de ordem 1 para cada mil destas jovens em ambos períodos. Já com relação aos nascimentos de ordens 2 e 3, neste grupo etário, observa-se uma diminuição no censo mais recente. Destaca-se, contudo, que ter um segundo ou terceiro filho quando se tem menos de 20 anos deve ser motivo de alerta qualquer que seja o contexto sociocultural da mulher.

Ainda na comparação temporal, atendendo ao comportamento da fecundidade segundo idade (isto é, a localização das curvas no eixo das idades), não há praticamente mudanças. A posição das curvas, como esperado, desloca-se à direita (para as mulheres mais velhas) à medida que aumenta a ordem do nascimento. 0 que importa salientar aqui é a mudança de nível destas taxas entre um período e o próximo. 0 exemplo mais claro está no grupo etário de 25 a 30 anos, cujas taxas de qualquer ordem de nascimento são sempre mais baixas em 2010.

A parte inferior do Gráfico 3 mostra o comportamento das taxas de ordens superiores (5 até 8), em que, como já assinalado, as curvas deslocam-se mais à direita conforme aumentam as ordens de nascimento. Importante salientar que a diferença de nível, neste caso, é menor do que a observada nas ordens mais baixas. No caso de ordem 5, praticamente não há variação se comparados 2000 e 2010 (Tabela 3 do Apêndice). Outro ponto é o deslocamento, em 2010, das curvas das ordens extremas (7 e 8 neste caso), claramente mais concentradas nas idades mais próximas do final do período reprodutivo. Estas pequenas diferenças seriam consistentes com os níveis menores para nascimentos de ordem baixa, como visto anteriormente; isto é, trata-se de um fenômeno iniciado pelas mulheres mais jovens, sendo que as mulheres de mais idade ainda mantêm níveis altos de fecundidade.

\footnotetext{
${ }^{7}$ Este procedimento, com dados de levantamentos amostrais e para um ano anterior à pesquisa, não é isento de problemas metodológicos, no entanto, é a melhor forma de verificar se existe mudança no calendário de fecundidade para mulheres em idade fértil.
} 
GRÁFICO 3

Taxas específicas de fecundidade por idade das mulheres indígenas, segundo ordem de nascimento Brasil - 2000-2010
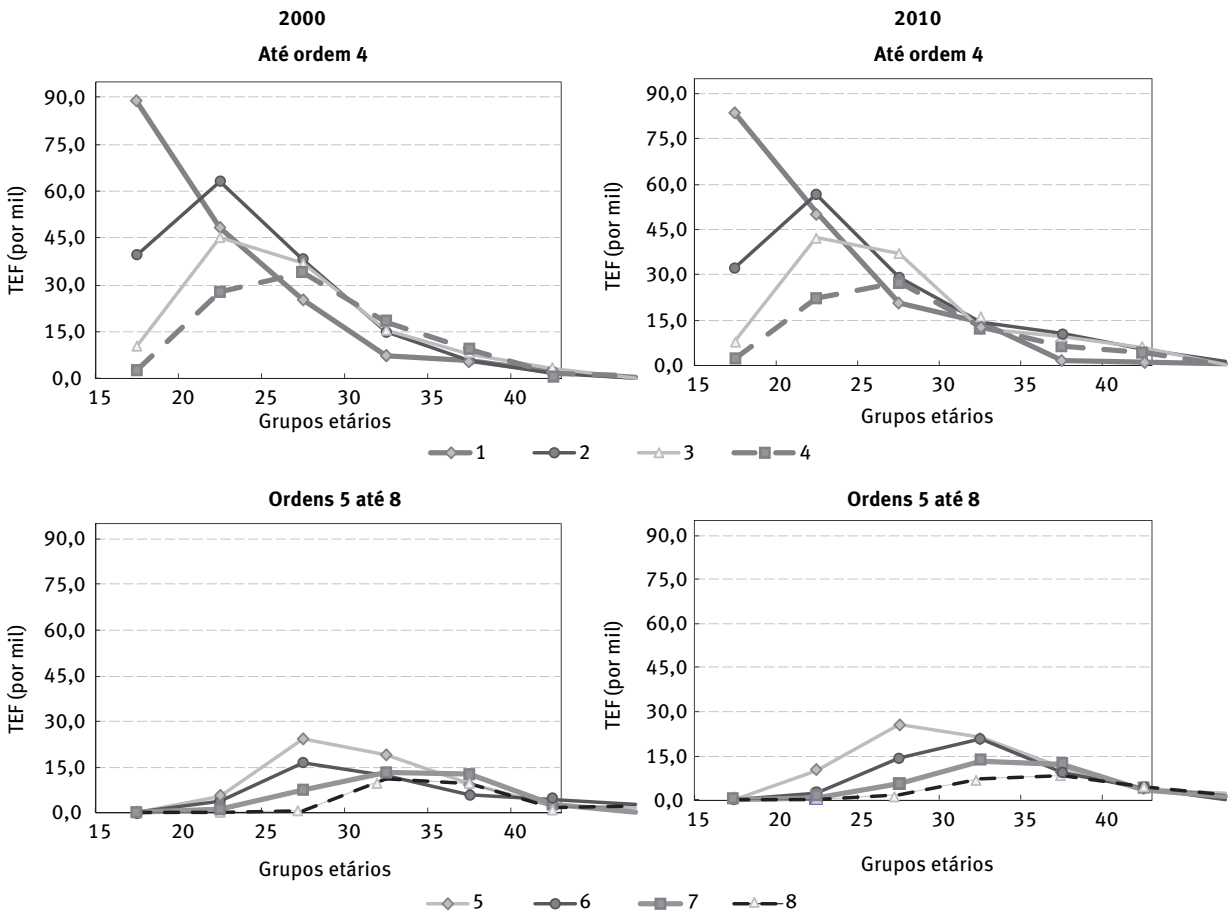

Fonte: IBGE. Censos Demográficos e Tabela 2 do Apêndice.

É importante salientar que o padrão revelado para o total da população indígena é produto, essencialmente, do comportamento da população rural, onde se concentra a vasta maioria das Terras Indígenas. Para confirmar esta observação, o Gráfico 4 apresenta os resultados para a população indígena rural, sempre para os anos 2000 e 2010.

As curvas do painel superior mostram significativa variação entre as duas datas: são, no geral, menores em 2010 e se deslocam à direita, indicando que, proporcionalmente, as maiores parturições tendem a se concentrar entre as mulheres mais velhas. Um fato a destacar refere-se aos nascimentos de primeira ordem para as jovens de 15 a 19 anos, cuja taxa não mudou no período, mostrando insistentes 90 primeiros nascimentos para cada mil jovens; mais da metade da probabilidade de ter um nascimento de primeira ordem está concentrada nestas idades, com ligeira tendência de aumento em 2010. A alta fecundidade neste grupo etário, similar à obtida para a população indígena total, indica que esse risco independe menos do lugar de residência (urbana ou rural) e mais de outros fatores não contemplados neste estudo.

Já a taxa correspondente aos nascimentos de ordem 2 - num indicativo de que a fecundidade reduziu-se ao chegar em 2010 - diminui notavelmente para estas jovens, passando de 63,0 para 39,6 no período. Para estas jovens, ter mais de um filho ainda 
é recorrente, mas o fenômeno é menos acentuado em 2010. Outro indicativo da queda da fecundidade indígena rural está nos níveis das taxas de ordens 3 e 4: em 2000, estas taxas encontravam-se acima de 45 por mil mulheres de 25 a 30 anos, ficando muito próximas de 30 por mil, em 2010. Note-se que na taxa de ordem 4, além de se registrar um claro deslocamento da curva para idades mais velhas, os valores são sensivelmente menores (linha pontilhada).

As taxas correspondentes a nascimentos de ordens superiores (5 ou mais), mais significativas entre mulheres mais velhas, não mostram variações importantes em suas magnitudes, mas sim, como visto no caso da população total, um pequeno deslocamento à direita. Dados os níveis de fecundidade relativamente altos na população indígena, observa-se, também, que nascimentos de ordens maiores ( 5 e 6, por exemplo) são frequentes entre mulheres de 30 a 35 anos em 2010. Isto é, coerente com os altos níveis registrados pela população indígena rural, observa-se que a fecundidade de mulheres em idades avançadas que já têm um relativamente alto número de filhos continua sendo importante.

\section{GRÁFICO 4}

Taxas específicas de fecundidade por idade das mulheres indígenas rurais, segundo ordem de nascimento

Brasil - 2000-2010
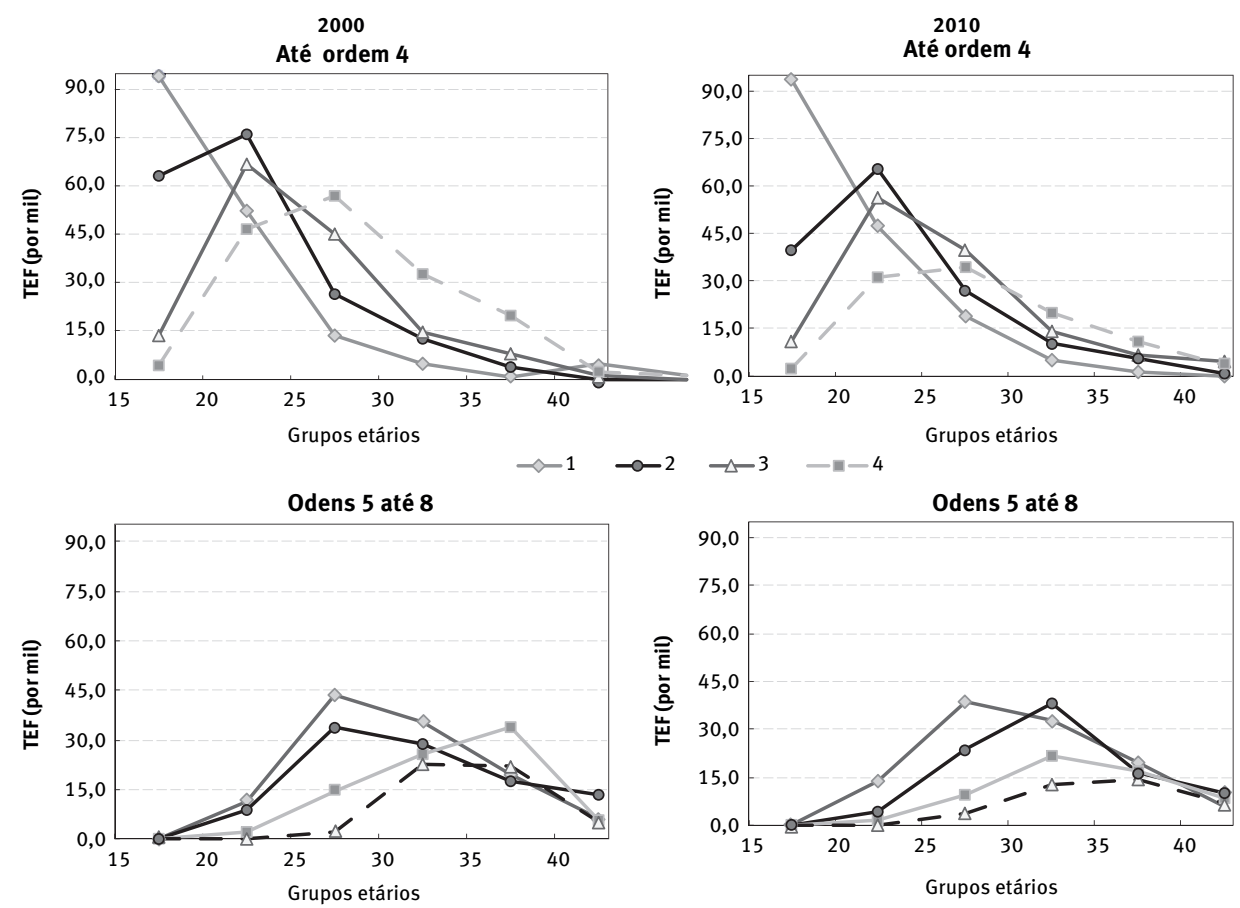

Fonte: IBGE. Censos Demográficos de2000 e 2010 e Tabela 2 do Apêndice. 
A fecundidade dos povos indígenas no futuro imediato

A possibilidade de ter dados de estoque sobre a fecundidade (o número médio de filhos nascidos vivos) e a fecundidade atual (o número de filhos tidos no último ano), seguindo os ensinamentos de Brass (1985), permite estimar qual seria o comportamento final em termos de parturição (ou número médio de filhos que a mulher tem). Nesta seção efetua-se um esforço para conseguir tais estimativas.

A racionalidade para obter este indicador se apoia no fato de que, se a fecundidade está diminuindo, como visto aqui, esta variável não deve diferir significativamente quando medida seja pelo número de filhos nascidos vivos tidos por uma mulher, seja pelo número de nascimentos ocorridos no último ano, sendo que ambas medidas tenderiam a ser similares, principalmente, para as idades mais jovens. ${ }^{8}$ Com este pressuposto, pode-se estimar a parturição completa para as gerações mais jovens, de forma que a fecundidade recente determinaria o padrão futuro das coortes com fecundidade ainda incompleta. ${ }^{9}$

Este procedimento baseia-se no fato de a declaração dos nascimentos ocorridos no último ano entre as mulheres jovens ser razoavelmente confiável e, ao mesmo tempo, estar mudando. A robustez deste procedimento é que, sem qualquer correção, os resultados $P$ e $\mathrm{F}$ ao serem comparados podem medir eventuais quedas na fecundidade.

The power of the procedure comes, however, when it is extended to birth order and hence parity progression ratios. If $F_{i}^{(n)}$ is written for the cumulated age specific fertility rates for births of $n$ 'th order and the $P_{i}^{(n)}$ are the proportion of women in the i'th age group having given birth to $n$ or more children, the relations between the $P_{i}^{(n)}$ and $F_{i}^{(n)}$ are similar to those between the $P_{i}$ and $F_{i}$, that is, between cohort and synthetic current cumulated fertility (BRASS, 1985, p. 71).

Os resultados estão detalhados no Gráfico 5, que ilustra o comportamento previsto para duas coortes jovens na época do Censo de 2010: mulheres com 25 a 29 e 30 a 35 anos. 0 Gráfico 5 inclui, também, a geração de mulheres de 45 a 49 anos que já estavam no fim do período reprodutivo. São apresentados dados para a população indígena total e a rural; este exercício não foi aplicado para a população urbana devido ao pequeno número de casos, o que provoca variações aleatórias, limitando a interpretação dos resultados.

Em qualquer caso, observa-se, até a data do censo, a proporção de mulheres que terminariam o período reprodutivo tendo ao menos um filho. No caso das mais jovens ( 25 a 29 e 30 a 34 anos), a maioria acabaria sendo mãe de ao menos um filho, tanto na área rural como na população total. No caso das mulheres mais velhas, $100 \%$ serão mães.

\footnotetext{
$\overline{8}$ Fecundidade acumulada por idade $\left(\mathrm{P}_{\mathrm{j}}\right)$ e fecundidade atual por idade $\left(\mathrm{F}_{\mathrm{i}}\right)$ na terminologia do método de Brass (1985).

${ }^{9}$ Seguindo a terminologia de Brass (1985, p. 70), estima-se $F\left(P_{j}\right)=P_{i}+\left(F-F_{j}\right)$, onde $F\left(P_{j}\right)$ representa a fecundidade total estimada (ou projetada) para uma coorte (ou geração) de mulheres com idade $i$ na época da pesquisa.
} 


\section{GRÁFICO 5}

Distribuição das mulheres na população indígena total e rural, por grupos de idade em 2010, segundo a probabilidade $(\mathrm{x} 100)$ de ter pelo menos o número de filhos indicado ao final do período reprodutivo

Brasil - 2010
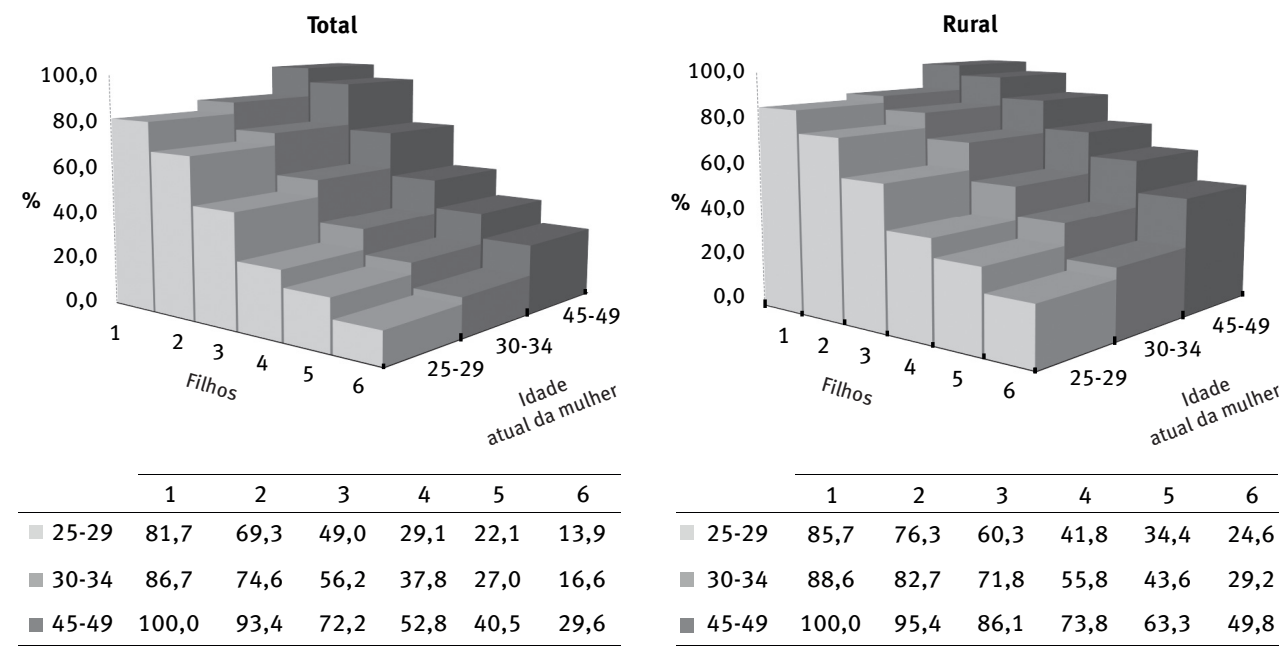

Fonte: IBGE. Censo Demográfico 2010 e Tabela 3 do Apêndice.

Limitando a análise à população indígena total, observa-se que o comportamento das duas coortes mais jovens é similar; os resultados indicam que, se os pressupostos estão certos, até o final do período reprodutivo, $29,1 \%$ das mulheres mais jovens terminariam tendo pelo menos quatro filhos. Para as mulheres cinco anos mais velhas, isto é, da coorte seguinte, a proporção daquelas com pelo menos quatro filhos é um pouco maior $(37,8 \%)$ e, no caso da coorte que já está no fim do período reprodutivo, chega a 52,8\%.

Se considerada a parturição seis ou mais, com os dados disponíveis no Censo de 2010, espera-se que, enquanto hoje $29,6 \%$ das mulheres mais velhas acabam tendo pelo menos seis filhos, as mulheres mais jovens poderão não repetir este padrão. De acordo com a parturição observada e a fecundidade recente destas mulheres, o percentual daquelas que, no final do período reprodutivo, venham a ter seis ou mais filhos será inferior ao das mulheres mais velhas de hoje: $13,9 \%$ e $16,6 \%$, respectivamente, para as mulheres hoje com 25 a 29 e 30 a 34 anos. Isto é, no geral, as mulheres mais jovens poderão encerrar seu ciclo reprodutivo com parturições menores. A proporção de mulheres com muitos filhos (ou altas parturições) tenderá a diminuir.

Guardadas as diferenças, mudanças parecidas prometem ocorrer para a população rural. Alguns exemplos: a porcentagem de mulheres que terminariam o período reprodutivo com pelos menos quatro filhos ainda seria alta: $55,8 \%$ para aquelas com 30 a 34 anos e $41,8 \%$ para as de 25 a 29 anos. Em ambos os casos, trata-se de proporções menores daquelas declaradas pelas mulheres que já estão no final do período reprodutivo: $73,8 \%$. Os dados anunciam que parturições muito altas também diminuirão significativamente no futuro próximo: as porcentagens de mulheres hoje mais jovens que teriam pelo menos 
seis filhos seriam de $24,6 \%$ ou $29,2 \%$, dependendo da coorte mais ou menos jovem. A proporção de mulheres mais velhas na área rural que acabam tendo pelo menos seis filhos é praticamente o dobro daquela obtida para as mulheres 20 anos mais novas.

Em suma, se as reduções manifestadas pelas mulheres mais jovens se mantiverem, é provável que a população indígena, tal qual o resto da população brasileira, manifeste uma queda da fecundidade que será possivelmente duradoura.

\section{Considerações finais}

Em que pesem as dificuldades de comparação, pode-se afirmar que a fecundidade das mulheres indígenas - tal como captada nos censos e considerando as tendências registradas para a área rural - dá sinais contínuos de diminuição. Os dados indicam que, na população indígena residente nas áreas urbanas, esta taxa já seria bastante baixa desde os anos 1990. Dado o escasso conhecimento sobre a população indígena brasileira residente em áreas urbanas, os valores encontrados para este segmento populacional precisam ser validados por outras fontes e, inclusive, mediante instrumental de outras áreas do conhecimento científico. É possível que um número médio inferior a três filhos tenha sido uma realidade desde a década de 1990, quando fontes censitárias são usadas; o que ainda está por ser explicado é a motivação desta fecundidade tão baixa e se aqueles autodeclarados indígenas são efetivamente membros de povos indígenas. Sabe-se que a população indígena, quando inserida num contexto urbano, frequentemente é um segmento excluído ${ }^{10}$ e segmentos excluídos, geralmente, não têm níveis baixos de fecundidade. Os resultados deste trabalho servem de base para algumas hipóteses a serem testadas, como, por exemplo, a limitação - forçada pelo contexto social imposto - às mulheres indígenas urbanas da implementação das preferências reprodutivas que costumeiramente caracterizam-se por um tamanho da família alto se comparado com a média da população brasileira.

Os resultados referentes à população rural, sem discriminação dos residentes nas Terras Indígenas, sinalizam uma incipiente, mas decidida transição da fecundidade a patamares menores. Ela ainda é alta em 2010 se comparada com o geral das populações contemporâneas; em níveis nacionais, não há na América Latina de 2010 países com taxas tão altas. A desagregação das taxas por ordem de nascimento, no entanto, revela os grupos em que a fecundidade estaria diminuindo mais acentuadamente: parturições de ordem 4 ou 5 são bastante mais baixas entre as mulheres em torno dos 30 anos.

\footnotetext{
$\overline{10}$ Foge ao escopo do presente trabalho se deter nesta problemática, no entanto, para o caso brasileiro pode-se consultar, por exemplo, o estudo de Véras (2006) e, ainda, os inventários das agências internacionais, como os da Organização Internacional do Trabalho (ILO, 2003), que consideram, entre os excluídos, a população indígena que se integra às cidades. Ver, também, Sosa-Sánchez e Menkes (2015).
} 
A fecundidade das adolescentes indígenas - cujo perfil social e cultural pouco se assemelha ao perfil médio das jovens brasileiras não indígenas - apresenta níveis altos; novamente, o ponto de comparação é a sociedade contemporânea brasileira (RODRÍGUEZ VIGNOLI, 2014; ALVES, 2014), parâmetro que pode não ser válido para os povos indígenas brasileiros. Contudo, se estas taxas são altas, ao decompô-las por ordem de nascimento percebe-se que, embora o risco de ter um primeiro nascimento permaneça imutável e alto, elevadas parturições estão perdendo a vez. 0 risco de ter um segundo ou terceiro nascimento nas idades 15 a 19 anos mostrou-se em declínio.

0 perfil da fecundidade mostrado neste trabalho é um primeiro passo para o entendimento do processo reprodutivo da mulher indígena no Brasil recente. Como mencionado, instrumental metodológico e raciocínio disciplinar diferente do demográfico devem olhar para estes resultados e aprofundar a pesquisa. Um melhor entendimento do contexto urbano do indígena brasileiro é uma prioridade; as preferências e os direitos reprodutivos dos casais constituem outra. Em que medida os povos indígenas querem e podem controlar 0 tamanho da prole é um dos aspectos que envolve este assunto. Os povos indígenas querem ter mais/menos filhos? Quais são as motivações para a definição de metas (maiores ou menores) sobre o tamanho da prole? Tais motivações seriam as mesmas já consagradas na literatura para a cultura moderna? Se não são, quais seriam? Certamente um trabalho de equipe multidisciplinar terá todas as condições de elucidar estas incógnitas.

\section{Referências}

ALVES, J. E. D. A fecundidade na adolescência no Brasil. Portal EcoDebate. 2014. Disponível em: 〈https://www.ecodebate.com.br/2014/05/16/a-fecundidade-na-adolescencia-no-brasil-artigode-jose-eustaquio-diniz-alves/>. Acesso em: 9 ago. 2016.

AZEVEDO, M. M.; RICARDO, F. Censo 2000 do IBGE revela contingente indígena pouco conhecido. Socioambiental. 2002. Disponível em: 〈https://site-antigo.socioambiental.org/nsa/ detalhe?id=303〉. Acesso em: 26 ago. 2016.

BRASIL, M.; TEIXEIRA, P. Migração dos povos indígenas e os censos demográficos de 1991 e 2000 : o caso das capitais estaduais. In: XV ENCONTRO NACIONAL DE ESTUDOS POPULACIONAIS. Anais... Caxambu: Abep, 2006. Disponivel em: 〈http://www.abep.nepo.unicamp.br/encontro2006/ docspdf/abep2006_828.pdf〉. Acesso em: 27 nov. 2015.

BRASS, W. Advances in methods for estimating fertility and mortality from limited and defective data. London: Centre for Population Studies, London School of Hygiene \& Tropical Medicine, 1985.

Note on Brass method of fertility estimation. In: BRASS, W.; COALE, A. J. et al. The demography of tropical Africa. Princeton: Princeton University Press, 1973. p. 140-142.

GONÇALVES, L. A. O.; GONÇALVES E SILVA, P. B. Movimento negro e educação. Revista Brasileira de Educação, Rio de Janeiro, n. 15, p. 134-158, jul./dez. 2000.

IBGE - Instituto Brasileiro de Geografia e Estatística. Tendências demográficas - uma análise dos indígenas com base nos resultados da amostra dos Censos Demográficos 1991-2000. Rio de Janeiro: Diretoria de Pesquisas, Coordenação de População e Indicadores Sociais, 2005 (Estudos e Pesquisas, n. 16). 
Wong, L.L.R. Tendências da fecundidade dos povos indígenas nos Censos Demográficos brasileiros de 1991 a 2010

Censo Demográfico 2010: características gerais dos indígenas. Resultados do universo. Rio de Janeiro, 2012.

Metodologia do Censo Demográfico 2010. Rio de Janeiro, 2013 (Série Relatórios Metodológicos, v. 41). Disponível em: 〈http://biblioteca.ibge.gov.br/visualizacao/livros/ liv81634.pdf〉.

INTERNATIONAL LABOUR OFFICE; ESTIVIL, J. Concepts and strategies for combating social exclusion. An overview. Geneva: International Labour Office, 2003. Disponivel em: 〈http://www. ilo.org/public/english/protection/socsec/step/download/96p1.pdf〉. Acesso em: 30 nov. 2015.

OLIVEIRA, N. M. P.; SANTOS, V. R.; AZEVEDO, M. M. Perfil demográfico socioeconômico das pessoas que se autodeclararam indígenas nos Censos Demográficos de 1991 e 2000. In: PAGLIARO, H.; AZEVEDO, M. M.; SANTOS, R. V. (Org.). Demografia dos povos indígenas no Brasil. Rio de Janeiro: Editora Fiocruz e Abep, 2005. p. 166-166.

OLIVEIRA, J. P. de. Pardos, mestiços ou caboclos: os índios nos censos nacionais no Brasil (18721980). Horizontes Antropológicos, Porto Alegre, n. 3, p. 60-83, 1997.

PAGLIARO, H. A recuperação demográfica dos povos indígenas do Brasil: a experiência dos Kaiabi do Parque Indígena do Xingu - Mato Grosso. In: XIII ENCONTRO NACIONAL DE ESTUDOS POPULACIONAIS. Anais... Ouro Preto: Abep, 2002. Disponivel em: 〈http://www.abep.nepo. unicamp.br/docs/anais/pdf/2002/com_ind_st14_pagliaro_texto.pdf). Acesso em: 21 nov. 2015.

A revolução demográfica dos povos indígenas: a experiência dos Kaiabi do Parque Indígena do Xingu, Mato Grosso. In: PAGLIARO et al. (Org.). Demografia dos povos indígenas no Brasil. Rio de Janeiro: Editora Fiocruz e Abep, 2005. p. 79-102.

PAGLIARO, H.; MENDAÑA, L. G. S.; RODRIGUES, D.; BARUZZI, R. G. Indian Park of Xingu: demographic behavior of the Waurá indians at the end of century XX. In: XXIV INTERNATIONAL GENERAL CONFERENCE. Proceedings... Salvador, 2001. p. 42-57.

Comportamento demográfico dos índios Kamaiurá, parque indígena do Xingu, Mato Grosso, Brasil (1970-1999). In: XIV ENCONTRO NACIONAL DE ESTUDOS POPULACIONAIS. Anais... Caxambu: Abep, 2004.

PAGLIARO, H.; JUNQUEIRA, C. Recuperação populacional e fecundidade dos Kamaiurá, povo Tupi do Alto Xingu, Brasil Central, 1970 - 2003. Revista Saúde e Sociedade, São Paulo, v. 16, n. 2, 2007.

PIZA, E.; ROSEMBERG, F. Cor nos censos brasileiros. Revista USP, São Paulo, n. 40, p. 122-137, dezembro/fevereiro 1999.

RODRÍGUEZ-VIGNOLI, J. Fecundidad adolescente en América Latina: una actualización. In: CAVENAGHI, S.; CABELLA, W. (Org.). Comportamiento reproductivo y fecundidad en América Latina: una agenda inconclusa. Rio de Janeiro: Alap, 2014. p. 33-66 (Serie e-Investigaciones, 3).

SILVA, J. Política de ação afirmativa para a população negra: educação, trabalho e participação no poder. In: VOGEL et al. (Org.). Trabalhando com a diversidade no Planfor: raça/cor, gênero e pessoas portadoras de necessidades especiais. São Paulo: Editora Unesp; Brasília: Flacso, 2001. Disponivel em: 〈http://www.flacso.org.br/data/biblioteca/336.pdf〉. Acesso em: 12 mar. 2006.

SOSA-SÁNCHEZ, I. A.; MENKES, C. B. “Como te ven te tratan”. Desigualdades sociales en servicios públicos de salud reproductiva en México.In: WONG, L. L. R.; ANTÓN, J. (Org.). La población afro descendiente y indígena en América Latina - puntos de reflexión para el debate sobre Cairo + 20. Alap, UNFPA, Ford Foundation, 2015. p. 185-206 (Serie e-Investigaciones, 4).

SOUZA, L. G. de; SANTOS, R. V. Perfil demográfico da população indígena Xavánte de Sangradouro - Volta Grande, Mato Grosso (1993-1997), Brasil. Cadernos de Saúde Pública, v. 17, n. 2, p. 355 366, 2001. 
TONON ZUANAZZI, P. A taxa de fecundidade no RS por regiões funcionais e características socioeconômicas: o desafio da transição demográfica. Indic. Econ. FEE, Porto Alegre, v. 42, n. 4, p. 109-122, 2015. Disponível em: 〈http://revistas.fee.tche.br/index.php/indicadores/article/ viewFile/3497/3544>. Acesso em: 21 nov. 2015.

UNITED NATIONS. Department of Economic and Social Affairs, Population Division. World population prospects: the 2015 revision. DVD Edition, 2015.

VÉRAS, M. P. Sociedade urbana: desigualdade e exclusão sociais. Caderno CRH, Salvador, n. 38, p. 79-114, jan./jun. 2003.

VITTI, V. T.; JUNQUEIRA, C. Mudanças demográficas e culturais no comportamento reprodutivo do povo Kamaiurá: uma análise por meio de coortes. In: WONG, L. L. R.; ANTÓN, J. (Org.). La población afro descendiente y indígena en América Latina - puntos de reflexión para el debate sobre Cairo + 20. Alap, UNFPA, Ford Foundation, 2015. p. 131-146 (Serie e-Investigaciones, 4).

WONG L. L. R.; MORELL, M. G. G. de; CARVALHO, R. L. Notas sobre o comportamento reprodutivo da população autodeclarada indígena - Censos Demográficos 1991 e 2000. Revista Brasileira de Estudos de População, Rio de Janeiro, v. 26, n. 1, p. 61-75, jan./jun. 2009.

\title{
Sobre a autora
}

Laura L. Rodríguez Wong é doutora em Demografia pela London School of Hygiene and Tropical Medicine e equivalência de mestre em Demografia pelo Centro Latino Americano e Caribenho de Demografia. Professora associada do Centro de Desenvolvimento e Planejamento Regional (Cedeplar) da Universidade Federal de Minas Gerais (UFMG).

\section{Endereço para correspondência}

Face/Cedeplar/UFMG

Av. Antônio Carlos, 6627, Pampulha

31270-901 - Belo Horizonte-MG, Brasil

\begin{abstract}
Indigenous population fertility trends according to the Brazilian Demographic Censuses from 1991 to 2010
\end{abstract}

Fertility of the self-declared indigenous women is analyzed based on Brazilian censuses from 1991 to 2010. Initially, as an approximation to the limitation that the quality of data may impose, population growth captured by these data sources is analyzed. There has been a bias on the self-declaration for 2000, more pronounced for the urban population, which may compromise the comparison with the 2010 data. In any case, this does not invalidate the analyses on fertility trends. Effectively, indigenous population fertility is decreasing even among the rural population living on the formal demarcation Indian lands. Also, urban indigenous fertility is highly differentiated from the rural. In this context, and adding the probable bias that might have contaminated the estimates in 2000 , the need for more investment in the study of this population is critical to answer, for instance who are the urban indigenous population captured in the censuses. Estimates of fertility according to birth order and parity indicate sharp fertility declines in the near future. Fertility of young indigenous women, without much differentiation 
at urban or rural places of residence, remains at very high levels compared to contemporary populations. This analysis calls for multidisciplinary studies to better understand the reproductive process of the Brazilian indigenous population.

Keywords: Demography of Indigenous population. Fertility. Birth order.

\section{Resumen}

Tendencias de la fecundidad de los pueblos indígenas en los censos demográficos brasileños del 1991 al 2010

Se considera la fecundidad de las mujeres autodeclaradas indígenas a partir de los censos brasileños de 1991 a 2010. Inicialmente -como una aproximación a la limitación de que la calidad de los datos puede imponer al análisis- se constata un sesgo de autodeclaración para 2000 , más pronunciado en la población urbana lo que compromete la comparación con datos del 2010, con todo, esto no invalida la continuación del análisis sobre fecundidad. Son fuertes los indicativos de una disminución de la fecundidad de los pueblos indígenas, incluso entre la población rural, es decir, el que reside en tierras indígenas. La fecundidad indígena urbana es muy diferenciada comparada con el rural; esto, junto con la sospecha de que los sesgos hayan contaminado las medidas producidas, apunta hacia la necesidad de una mayor inversión en el estudio de esta población: ¿quién es la población indígena urbana? Las estimaciones por orden de nacimiento y paridez indican, para un futuro próximo, disminución de la fecundidad. La fecundidad de las mujeres indígenas jóvenes, sin mucha diferenciación entre residencia urbana o rural, se mantiene en niveles muy elevados si comparados con poblaciones contemporáneas. Este análisis clama por estudios multidisciplinarios para comprender mejor el proceso reproductivo de los pueblos indígenas brasileños.

Palabras clave: Demografía indígena. Fecundidad. Orden de nacimiento. Brasil.

Recebido para publicação em 02/12/2015

Recomendado para publicação em 19/07/2016

Aceito para publicação em 21/09/2016 


\section{Apêndice}

TABELA 1

Número médio de filhos tidos pelas mulheres indígenas para três coortes com idades em 1991 como indicado e captados em 1991, 2000 e 2010, por situação de domicílio

Brasil - 1991-2010

\begin{tabular}{|c|c|c|c|c|c|c|c|c|c|}
\hline \multirow{3}{*}{$\begin{array}{c}\text { Idade em } \\
\text { anos em } \\
2010\end{array}$} & \multicolumn{9}{|c|}{ Idade em anos em 1991 (1) } \\
\hline & \multicolumn{3}{|c|}{ Total } & \multicolumn{3}{|c|}{ Urbano } & \multicolumn{3}{|c|}{ Rural } \\
\hline & 15 a 19 & 20 a 24 & 25 a 29 & 15 a 19 & 20 a 24 & 25 a 29 & 15 a 19 & 20 a 24 & 25 a 29 \\
\hline 15 a 19 & 0,49 & - & - & 0,28 & - & - & 0,56 & - & - \\
\hline 20 a 24 & 1,37 & 1,60 & - & 1,01 & 1,02 & - & 1,76 & 1,82 & - \\
\hline 25 a 29 & 2,25 & 2,34 & 2,87 & 1,75 & 1,74 & 1,98 & 2,96 & 2,98 & 3,28 \\
\hline 30 a 34 & 2,92 & 3,07 & 3,21 & 2,22 & 2,46 & 2,41 & 3,79 & 4,14 & 4,13 \\
\hline 35 a 39 & 3,59 & 3,42 & 3,55 & 2,69 & 2,68 & 2,85 & 4,62 & 4,61 & 4,98 \\
\hline 40 a 44 & - & 3,78 & 3,88 & - & 2,90 & 3,15 & - & 5,09 & 5,17 \\
\hline 45 a 49 & - & - & 4,22 & - & - & 3,45 & - & - & 5,35 \\
\hline
\end{tabular}

Fonte: IBGE, Banco de Dados Agregados, Sistema IBGE de Recuperação Automática - Sidra. Censos Demográficos de 1991,2000 e 2010. (1) Idades captadas em 1991. As parturições para períodos intermediários foram estimadas como o ponto médio do intervalo decenal.

TABELA 2

Taxas específicas de fecundidade (TEF) e distribuição relativa da TEF das mulheres indígenas, segundo grupos de idade e situação de domicílio

Brasil - 1991-2010

\begin{tabular}{|c|c|c|c|c|c|c|}
\hline \multirow{2}{*}{$\begin{array}{l}\text { Grupos de idade em anos } \\
\text { e situação de domicílio }\end{array}$} & \multicolumn{3}{|c|}{ TEF (por mil) } & \multicolumn{3}{|c|}{ Distribuição relativa (\%) } \\
\hline & 1991 & 2000 & 2010 & 1991 & 2000 & 2010 \\
\hline \multicolumn{7}{|l|}{ Total } \\
\hline 15 a 19 & 192,7 & 159,3 & 149,3 & 18,0 & 20,6 & 19,4 \\
\hline 20 a 24 & 254,3 & 198,4 & 193,4 & 23,7 & 25,6 & 25,1 \\
\hline 25 a 29 & 223,9 & 182,1 & 167,8 & 20,9 & 23,5 & 21,8 \\
\hline 30 a 34 & 159,1 & 115,7 & 126,0 & 14,8 & 14,9 & 16,4 \\
\hline 35 a 39 & 145,6 & 81,7 & 83,7 & 13,6 & 10,5 & 10,9 \\
\hline 40 a 44 & 61,7 & 27,7 & 41,3 & 5,7 & 3,6 & 5,4 \\
\hline 45 a 49 & 36,3 & 9,6 & 7,8 & 3,4 & 1,2 & 1,0 \\
\hline TFT & 5,4 & 3,9 & 3,8 & 100 & 100 & 100,0 \\
\hline \multicolumn{7}{|l|}{ Urbano } \\
\hline 15 a 19 & 124,5 & 120,5 & 110,6 & 21,5 & 22,8 & 19,6 \\
\hline 20 a 24 & 159,0 & 143,1 & 149,8 & 27,4 & 27,1 & 26,5 \\
\hline 25 a 29 & 115,3 & 139,5 & 125,1 & 19,9 & 26,4 & 22,1 \\
\hline 30 a 34 & 82,9 & 66,8 & 83,9 & 14,3 & 12,6 & 14,9 \\
\hline 35 a 39 & 72,4 & 39,6 & 61,0 & 12,5 & 7,5 & 10,8 \\
\hline 40 a 44 & 19,8 & 15,3 & 32,1 & 3,4 & 2,9 & 5,7 \\
\hline 45 a 49 & 5,6 & 3,6 & 2,5 & 1,0 & 0,7 & 0,4 \\
\hline TFT & 2,9 & 2,6 & 2,8 & 100,0 & 100,0 & 100,0 \\
\hline \multicolumn{7}{|l|}{ Rural } \\
\hline 15 a 19 & 216,8 & 208,9 & 173,1 & 16,2 & 17,2 & 18,1 \\
\hline 20 a 24 & 292,9 & 283,0 & 227,2 & 21,9 & 23,2 & 23,7 \\
\hline 25 a 29 & 277,2 & 249,3 & 205,8 & 20,8 & 20,5 & 21,5 \\
\hline 30 a 34 & 202,2 & 209,1 & 169,1 & 15,2 & 17,2 & 17,6 \\
\hline 35 a 39 & 190,1 & 175,8 & 112,1 & 14,2 & 14,4 & 11,7 \\
\hline 40 a 44 & 89,2 & 65,1 & 55,2 & 6,7 & 5,3 & 5,8 \\
\hline 45 a 49 & 66,2 & 26,7 & 16,0 & 5,0 & 2,2 & 1,7 \\
\hline TFT & 6,7 & 6,1 & 4,8 & 100,0 & 100,0 & 100,0 \\
\hline
\end{tabular}

Fonte: IBGE, Banco de Dados Agregados, Sistema IBGE de Recuperação Automática - Sidra. Censos Demográficos de 1991, 2000 e 2010. 
TABELA 3

Taxas específicas de fecundidade da população indígena total e rural, por grupos de idade, segundo ordem de nascimento

Brasil - 2000-2010

\begin{tabular}{|c|c|c|c|c|c|c|c|c|}
\hline \multirow{2}{*}{$\begin{array}{l}\text { Ordem de } \\
\text { nascimento }\end{array}$} & & \multicolumn{7}{|c|}{ Taxas específicas de fecundidade (por mil) } \\
\hline & & $\begin{array}{c}15 \text { a } 19 \\
\text { anos }\end{array}$ & $\begin{array}{c}20 \text { a } 24 \\
\text { anos }\end{array}$ & $\begin{array}{c}25 \text { a } 29 \\
\text { anos }\end{array}$ & $\begin{array}{c}30 \text { a } 34 \\
\text { anos }\end{array}$ & $\begin{array}{c}35 \text { a } 39 \\
\text { anos }\end{array}$ & $\begin{array}{c}40 \text { a } 44 \\
\text { anos }\end{array}$ & $\begin{array}{c}45 \text { a } 49 \\
\text { anos }\end{array}$ \\
\hline \multicolumn{9}{|c|}{ População total } \\
\hline \multirow{10}{*}{2000} & 1 & 88,59 & 48,40 & 25,35 & 7,29 & 5,86 & 1,99 & 0,32 \\
\hline & 2 & 39,49 & 63,09 & 37,86 & 14,67 & 5,54 & 1,49 & 0,00 \\
\hline & 3 & 10,27 & 45,01 & 36,70 & 15,26 & 7,51 & 3,15 & 0,00 \\
\hline & 4 & 2,49 & 27,61 & 33,90 & 18,12 & 9,20 & 1,66 & 0,83 \\
\hline & 5 & 0,00 & 5,25 & 24,44 & 18,97 & 9,75 & 2,37 & 1,59 \\
\hline & 6 & 0,26 & 3,98 & 16,31 & 12,12 & 6,13 & 4,64 & 2,67 \\
\hline & 7 & 0,26 & 1,10 & 7,71 & 13,20 & 12,72 & 2,76 & 0,25 \\
\hline & 8 & 0,00 & 0,00 & 0,83 & 11,01 & 9,84 & 1,93 & 2,42 \\
\hline & 9 & 0,00 & 0,10 & 0,71 & 6,40 & 8,97 & 2,98 & 0,00 \\
\hline & $10+$ & 0,00 & 0,34 & 0,83 & 2,82 & 9,98 & 8,28 & 3,56 \\
\hline \multirow{10}{*}{2010} & 1 & 83,68 & 50,70 & 20,63 & 14,45 & 1,81 & 0,96 & 0,53 \\
\hline & 2 & 32,24 & 56,51 & 29,02 & 14,33 & 10,42 & 5,37 & 1,33 \\
\hline & 3 & 8,20 & 42,52 & 36,89 & 12,13 & 9,78 & 5,83 & 0,27 \\
\hline & 4 & 2,25 & 22,38 & 27,75 & 12,63 & 6,60 & 4,02 & 0,13 \\
\hline & 5 & 0,09 & 9,78 & 25,99 & 21,31 & 11,25 & 3,39 & 2,59 \\
\hline & 6 & 0,00 & 2,38 & 14,27 & 20,68 & 9,59 & 4,02 & 0,20 \\
\hline & 7 & 0,00 & 0,85 & 5,92 & 13,08 & 11,98 & 3,51 & 1,06 \\
\hline & 8 & 0,00 & 0,03 & 2,10 & 7,23 & 8,22 & 4,69 & 2,13 \\
\hline & 9 & 0,00 & 0,00 & 0,37 & 2,66 & 4,50 & 1,47 & 1,06 \\
\hline & $10+$ & 0,00 & 0,00 & 0,00 & 1,87 & 7,04 & 8,03 & 0,66 \\
\hline \multicolumn{9}{|c|}{ População rural } \\
\hline \multirow{10}{*}{2000} & 1 & 94,02 & 52,20 & 13,46 & 5,16 & 0,70 & 4,96 & 1,18 \\
\hline & 2 & 63,03 & 76,09 & 26,82 & 12,64 & 3,92 & 0,00 & 0,00 \\
\hline & 3 & 13,62 & 66,63 & 45,20 & 14,49 & 7,85 & 1,24 & 0,00 \\
\hline & 4 & 4,62 & 46,73 & 57,15 & 32,78 & 20,04 & 2,48 & 1,18 \\
\hline & 5 & 0,00 & 11,09 & 43,79 & 35,23 & 19,34 & 6,20 & 1,65 \\
\hline & 6 & 0,00 & 8,89 & 34,05 & 28,85 & 17,66 & 13,24 & 9,89 \\
\hline & 7 & 0,00 & 2,20 & 14,66 & 25,66 & 33,64 & 5,79 & 0,94 \\
\hline & 8 & 0,00 & 0,00 & 2,01 & 22,59 & 22,14 & 5,38 & 5,65 \\
\hline & 9 & 0,00 & 0,24 & 0,50 & 16,20 & 22,42 & 8,07 & 0,00 \\
\hline & $10+$ & 0,00 & 0,00 & 1,00 & 7,24 & 24,67 & 21,51 & 9,65 \\
\hline \multirow{10}{*}{2010} & 1 & 93,52 & 47,19 & 19,05 & 4,89 & 1,26 & 0,00 & 1,31 \\
\hline & 2 & 39,64 & 65,29 & 26,70 & 10,59 & 5,78 & 0,85 & 1,31 \\
\hline & 3 & 10,94 & 56,30 & 39,62 & 14,01 & 6,83 & 4,66 & 0,66 \\
\hline & 4 & 2,31 & 31,27 & 34,28 & 19,79 & 11,13 & 3,67 & 0,33 \\
\hline & 5 & 0,14 & 13,69 & 38,83 & 32,82 & 19,85 & 6,08 & 2,79 \\
\hline & 6 & 0,00 & 4,01 & 23,60 & 38,20 & 16,70 & 9,89 & 0,49 \\
\hline & 7 & 0,00 & 1,43 & 9,69 & 21,75 & 16,91 & 8,48 & 2,62 \\
\hline & 8 & 0,00 & 0,06 & 3,69 & 12,62 & 14,18 & 6,93 & 5,25 \\
\hline & 9 & 0,00 & 0,00 & 0,66 & 4,48 & 5,88 & 3,25 & 2,62 \\
\hline & $10+$ & 0,00 & 0,00 & 0,00 & 3,67 & 11,97 & 15,97 & 0,98 \\
\hline
\end{tabular}

Fonte: IBGE. Microdados dos Censos Demográficos de 2000 e 2010. 